\title{
French astronomers to rank facilities
}

[MUNICH] French astronomers are about to carry out a scientific ranking of the groundbased and space-based projects in which they participate - or are considering participation - to help to target required cuts totalling FFr20 million (US\$3.3 million) in this year's astronomy budget.

The move is the first step towards a coordinated strategy for astronomy in France and, according to some, could become a model for a Europe-wide effort. It will involve about 200 astronomers, and will take place at a meeting this week organized by the Centre National de la Recherche Scientifique (CNRS) in Arcachon, southwest France.

Last autumn, France's astronomy community was shocked by a demand from the research minister, Claude Allègre, that France cut its annual subscription to the European Southern Observatory (ESO) by a quarter, from FFr130 million to FFr100 million.

But ESO's budget is shared between states according to a fixed formula, and Allègre was persuaded that such a large cut across the board would be rejected. Instead, at an extraordinary meeting of ESO's council last month the representatives of ESO's eight member states agreed to cut 2.5 per cent from each state's contributions (see below).

Allègre was appeased by a suggestion brokered by Jean-François Minster, director of the Institut des Science de l'Universe. This involves saving a third of the FFr30 million he demanded by withdrawing French participation from two instruments on ESO's Very Large Telescope (VLT), the building of which is well under way.

The instruments, which are paid for from national rather than ESO budgets, are a

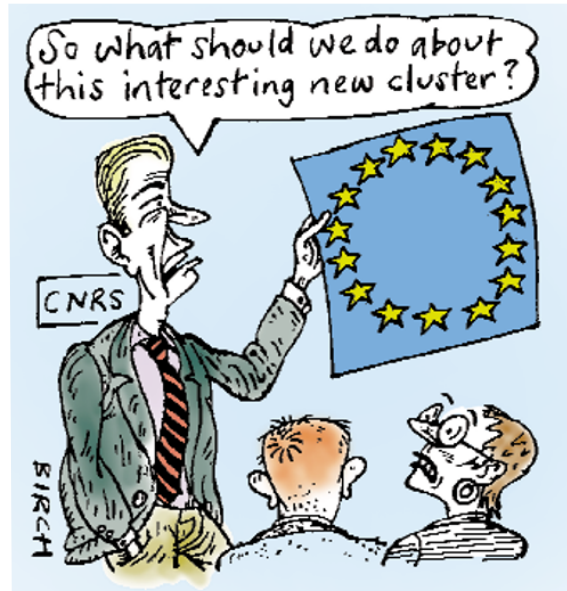

spectrograph and the third auxiliary telescope of the VLT's state-of-the-art interferometry system. France's research ministry must decide in the next few weeks whether to endorse these cuts, and also where to make a further cut of FFr20 million.

The ranking of projects to be conducted at the Arcachon meeting will help in making these immediate decisions. But it will also form a basis for a new strategy for French astronomy in the next decade, with wider implications for European and international joint projects.

Bernard Fort, director of the Institute of Astrophysics of the Observatoire de Paris, and French representative on ESO's council, says the field is wide open. "The meeting will consider the scientific output of big spacebased and ground-based planned projects like FIRST [the European Space Agency's planned Far Infrared Observatory], the large millimetre arrays, the next generation space

\section{Observatory vows to keep telescope schedule}

[MUNICH] The European

Southern Observatory (ESO) must tighten its belt this year to keep construction of its important new project, the Very Large Telescope (VLT), on schedule.

This follows a move by ESO's council to cut 2.5 per cent from the organization's budget for 1998 in response to heavy cuts in France's support for 'big science' projects (see above).

But ESO is optimistic that the shortfall will not disrupt its science programme. "We handled a five per cent cut last year when Germany had budgetary problems," says Norbert König, ESO's administrative director, "and we will handle the new cut". $\mathrm{He}$ adds, however, that ESO would find it difficult to respond to regular cuts every time one of its member states has a budgetary crisis.

Operation of the first of

VLT's telescopes is still scheduled for May, with full interferometry expected in 2003. But the possible withdrawal of France from the building of key elements of the interferometry system means that ESO must find new partners if it is to keep to its timetable.

ESO is also looking ahead to its scientific goals after VLT. One decision to be taken in the next year or so is how far to collaborate with the United States on plans for large-millimetre-array telescopes.

But ESO will also consider its general role in European astronomy, seeking a balance with national astronomy programmes.

It is keeping the debate low-key because of the issue's sensitivity. Opinion is polarized between those who think a larger fraction of national astronomy budgets should be targeted towards ESO, and those who see a need to maintain strong independent national programmes. A.A. telescope, and other facilities which all observe the same astronomical events, the formation of stars and galaxies," he says.

One idea being floated is a reduction in French support for instruments on FIRST, which is scheduled to cost France FFr300 million on top of its ESA subscription.

Minster says the meeting will discuss how France can best address important middleterm questions, "and how we must change the structure of French laboratories to achieve this". For example, he says, "we must consider issues such as whether there are too many ground-based telescopes in the international arena, and where to concentrate French efforts".

Given the strain on astronomy budgets throughout Europe, some are now arguing for a Europe-wide ranking exercise of ground-based and space-based astronomy, analogous to the Bahcall report conducted by the National Science Foundation in the United States in the early 1990s.

For example, Steven Beckwith, a director of the Max Planck Institute for Astronomy in Heidelberg, and the newly elected director of the Hubble Space Telescope, says that such a ranking "is long overdue in Europe". ESA's science director, Roger Bonnet, says that ESA's science plan is broadly coordinated with ESO priorities, as well as those of other communities with interest in space science, and so no additional ranking is necessary.

Some astronomers insist that such an exercise should not be conducted across Europe, as each country should decide its own spending according to criteria that are not merely scientific, but may also include industrial interests.

Lodjewik Woltjer, former chairman of ESA's Space Science Advisory Committee, and an associate of the Observatoire de Haute Provence, says the organization of astronomy in Europe is much more complicated than in the United States. "You couldn't afford to give a negative priority to any project in which one countryhas particular scientific - and industrial-interests."

But others argue that a European vision should supersede national interests. Having already joined forces with ESA and ESO, European astronomers should "acknowledge European rather than national priorities", says Giovanni Bignami, science director of the Italian Space Agency and professor of astrophysics at the University of Pavia.

But there is a further obstacle to any Europe-wide astronomy ranking, namely the lack of an obvious forum in which it could take place. "Perhaps we should consider an independent body like the European Science Foundation", suggests Manfred Otterbein, director of space science at the German space agency DLR.

Alison Abbott 